\title{
Advances in Multiple Criteria Decision Making for Sustainability: Modeling and Applications
}

\author{
Kao-Yi Shen ${ }^{1, *(1)}$ and Gwo-Hshiung Tzeng ${ }^{2}$ \\ 1 Department of Banking and Finance, Chinese Culture University (SCE), Taipei 11114, Taiwan \\ 2 Graduate Institute of Urban Planning, National Taipei University, New Taipei City 23741, Taiwan; \\ ghtzeng@mail.ntpu.edu.tw \\ * Correspondence: atrategy@gmail.com; Tel.: +886-(2)2700-5858 (ext. 8676)
}

Received: 10 May 2018; Accepted: 11 May 2018; Published: 16 May 2018

\begin{abstract}
With the surging complexity of real-world problems in important domains such as sustainability, there is a need to leverage advanced modern computational methods or intelligent techniques to support decisions or policy-making. In this Special Issue, 15 selected and formally peer-reviewed papers contribute their novelty and findings, by applying various advanced decision methods or computational techniques to resolve different sustainability problems. Despite the innovations of the proposed models, most of the selected papers involve domain expert's opinions and knowledge with in-depth discussions. These case studies enrich the practical contributions of this Special Issue.
\end{abstract}

Keywords: sustainable development; multiple criteria decision making (MCDM); problem-solving; optimization; decision aid; computational intelligence; machine learning (ML); artificial intelligence (AI); soft computing; fuzzy sets; rough set theory (RST)

\section{Introduction}

Sustainability-related issues address environment, ecology, energy, management, marketing, economics, finance, healthcare, research and development (R\&D), transportation, and many other vital topics. At the conceptual level, there are many approaches to observe, explain, analyze, and tackle these not only influential but also complicated issues [1]. In fact, nearly everyone would agree that the sustainability issues mentioned above involve multiple aspects, also termed as criteria; thus, how to devise a suitable model or method considering those associated aspects matters. In social science research, statistical approaches might be the most prevailing ones. Nevertheless, statistical models are usually constrained by various presumptions or limitations. Examples are the linearity and the independence relationship among the included variables, which might yield unwanted biases while those factors are interdependent [2,3]—a common practice in most real-world problems.

To overcome the limitations of the conventional approach in social science, this Special Issue emphasizes advanced modeling or resolving practical sustainability issues by embracing various single, combined, or integrated methods/techniques to overcome the mentioned limitations above. Broadly speaking, since multiple variables often exist in a well-defined sustainability problem, it is reasonable to adopt the multiple criteria decision making (MCDM) approach [4]. In addition, with the surging amount of available data, machine learning (ML) or artificial intelligence (AI) techniques begin to gain prominence in various applications [5]. These data-driven techniques are capable of modeling non-linear datasets; also, they do not require presumed probabilistic distributions. With those advanced computational techniques, researchers have more options, other than statistics, to deal with complex sustainability problems. 
Although ML or AI-based techniques have advantages in exploring and unraveling the intricate logic/patterns behind a practical problem, in many cases, the knowledge or preference of human experts (or stakeholders) cannot be overlooked, especially in those policy-making fields. In this regard, a conventional MCDM approach offers various methods for experts to contribute their opinions/knowledge to a specific problem. Usually, owing to the limited rationality assumption of human beings [6], decision-makers (DMs) are requested to provide pairwise comparisons among the involved criteria instead of assigning the relative importance of each variable directly, to form the overall MCDM evaluation models. One of the prevailing pairwise comparison approaches is the analytic hierarchy process (AHP) [7]; the subsequent analytic network process [8] (a generalized form of AHP that can model the interrelationship among variables), also proposed by Saaty, has been applied in numerous research. Some other MCDM methods, similar to AHP/ANP, require human experts' opinions to identify the relative importance or interrelationship among criteria (e.g., DEMATEL [9] and DEMATEL-based ANP [10]). During the knowledge retrieval phase, the interactions between experts and the model are critical. One of the obstacles is the degree of the relative importance or influence of one criterion over the others, usually expressed in linguistic terms by experts, which would need soft computing techniques (e.g., fuzzy set, rough set, and grey set) to accomplish this task [11,12]. Thus, in this Special Issue, several studies adopt soft computing techniques to incorporate the opinions of experts for constructing their models.

The above-discussed reasons highlighted the importance of adopting, combining, or integrating various advanced computational techniques, through the interactions between experts and the model/system, to resolve the growing complexity of practical sustainability problems [13]. We are grateful for the journal—Sustainability - to offer such an open and academic platform for researchers to contribute and exchange their recent findings in the framework of MCDM. During the editorial process, this Special Issue attracted 42 submissions from different continents. With the timely and academic support from voluntary reviewers and assistant editors, we thus reached a consensus with professional judgment for each submission; their efforts are genuinely appreciated. Eventually, 15 formally peer-reviewed articles met the journal's requirements and were published online. The following section will discuss the central theme and contribution of each article of this Special Issue.

\section{Contributions}

The first paper [14] addresses the risk assessment of power distribution systems by considering four major predefined risk indices. As stated by the authors, the intermittency and variability of the distributed generators of a distribution system are the primary sources of risk. How to model and simulate this output variability and uncertainty is a critical issue to secure the sustainability of such a system. An improved point estimate method (PEM) is adopted to optimize the simulation outcomes. The simulation results outperform the other benchmarked risk assessment methods with discussions.

The next paper [15] tackles the topic of eco-efficiency, where a data envelopment analysis (DEA) [16] based optimization model is adopted to balance the operational and environmental efficiency. In addition, owing to the different levels of stringent or harsh requirements of different industries (or the same industry in different countries), those requirements can be set as constraints for DMs to apply this model in various circumstances with flexibility. A case of agricultural production systems is illustrated by using the proposed model. The DEA approach may be regarded as one of the multiple objective decision making (MODM) methods [17], and the advantages of DEA are leveraged in this paper for resolving the eco-efficiency problem.

The following paper [18] aims at devising an MCDM-based economic analysis for the solar PV energy system in India. The rising demand of electricity for industrial productions and consumers in India urges its government to evaluate various renewable power systems for the sustainability concern. To serve as a reference for policy-making, it not only conducts a conventional economic analysis (e.g., NPV and IRR analyses) but also completed an AHP-based model by collecting professional opinions from experts. Multiple aspects are considered in reaching the valuable conclusion. 
The fourth paper [19] is contributed by the Italian researchers; its topic falls in the category of finance/investment, where the concept of social-responsibility (or termed as "ethical finance" by the authors) is addressed for sustainability. In which, the assessment of a real estate extended financial investment is gauged by evaluating multiple criteria, to see if such an investment is qualified to be included in the socially-responsible funds. A case study, in the municipality of a city in Rome, is analyzed for illustrating the proposed idea.

The next paper [20] puts its focus on enhanced hybrid and cooperated searching strategies-for the nurse rostering problem (also known as the nurse scheduling problem)—is contributed. Although the direct tie between this problem and sustainability is not highlighted, the proposed algorithm shows superior results by testing a benchmarking data set against the other well-known methods. More specifically, two types of hybrid metaheuristic approaches (i.e., the harmony search technique and artificial immune system) are proposed and tested. Its result suggests that the combination of the two mentioned approaches outperformed a single one, which also echoes the central theme of this Special Issue by fusing more than one advanced technique to solve a complex problem.

The two papers which follow are both invited articles. The sixth paper [21] applied a hybrid MCDM approach that combines grey DEMATEL, multi-attribute border approximation area comparison (MABAC), and sensitivity analysis to support the ranking decisions of genetically modified (GM) Argo by-products R\&D projects. This study highlights the importance of the GM Argo portfolio management considering not only the $R \& D$ aspect but also social responsibility. The primary contributions of this study are twofold: (1) the senior experts' involvements from the renowned National Agro Research Institute in India accredited the derived result and (2) the proposed novel hybrid MCDM model. Thus, this study fulfills its goal of forming a reliable hybrid decision support model to evaluate strategic project portfolio selection (SPPS) of Agro by-products. The proposed framework seems to be promising considering the rising awareness of corporate social responsibility (CSR) in many industries.

The seventh paper [22] also attempts to resolve the R\&D project selection problem; it presumes that the superior $R \& D$ projects are a crucial factor for technology companies to sustain in the long-term. Also, the risk-return preference should be different in each tech company; thus, how to measure and model individual risk attitude should be incorporated in an evaluation system. To meet this goal, it adopts a hybrid approach: the combination of decision-making trial and evaluation laboratory (DEMATEL) and consistent fuzzy preference relations based analytic network process (CFPR-ANP) methods. Similar to the previous paper [21], a soft computing technique (fuzzy preference measure) is adopted to serve as a communication platform between the users and the model. Besides, during the evaluation phase, the combined complex proportional assessment (COPRAS-G) method is applied to work with fuzzy grey relations to resolve conflicts among stakeholders.

The central theme of the eighth paper [23] is about the process of manufacturing in a Computer-Aided Process Innovation (CAPI) environment, which addresses the topic of sustainable production. This study involves knowledge retrieval by domain experts; as a result, the fuzzy linguistic computing is applied during the evaluation. The widely adopted AHP method is constructed to form an MCDM model. A case regarding micro-turbine machining is analyzed by the proposed hybrid approach with managerial discussions.

The following paper [24], aiming at the topic of sustainable scheduling of cloth production, chooses the MODM approach to resolve the other aspect of manufacturing. The problem setting includes multiple dimensions, including the technical, environmental, operational ones. A novel multi-objective genetic algorithm with tabu-enhanced iterated greedy local search strategy (MOGA-TIG) is proposed with several computational experiments. During those experiments, the other two well-known algorithms were benchmarked. The result shows satisfactory outcomes with discussions.

The tenth paper [25], also an invited article, turns its attention from manufacturing to the health sector, which attempts to improve the electronic health record (EHR) solution from users' perspectives. Its theoretical foundation is based on the well-known TOE (technology-organization-environment) 
theory [26]. The proposed hybrid MCDM model emulates the concept of ANP, derived from the DEMATEL (decision-making trial and evaluation laboratory) technique to form the DEMATEL-based ANP model; also the modified VIKOR method is integrated to identify the priority gaps for guiding improvements.

In the next, the eleventh paper [27] resolves the credit rating problem for small enterprises in China, considering multiple criteria. As stated by the authors, the available financial records of small enterprises are usually neither sufficient nor reliable. To solve this obstacle, it proposes a novel statistical approach based on the rank sum test and entropy weighting method-a nonparametric approach. One of its merits is the avoidance of the assumption of normality associated with most common credit rating methods, which contributes in serving financial institutes in dealing with the credit loan applications from small enterprises.

The paper which follows [28] attempts to solve the optimization problem of sustainable urbanization strategies by considering multiple criteria. Since urbanizing is thriving in many places in China, the differences in multiple aspects (e.g., economic, ecology, society, resource, and religion) will yield various outcomes to entice population migrations to a central city, which thereby brings subsequent urbanization and developments to its local/neighbor regions. From the perspective of sustainability, it is prudent to develop strategic optimization guidance based on the local administration's long-term planning. This study adopts Particle Swarm Optimization (PSO) and extended the hybrid MODM method to solve the optimization problem in a bi-uncertain environment, where the uncertainty is modeled by fuzzy random variables. A case study is demonstrated to show the advantages of the proposed hybrid approach.

The thirteenth paper [29] deals with the problem of the recycling rate of end-of-life vehicles (ELVs) in China. The recent booming economy of China has many side effects; one of the severe consequences, is the environmental pollution, especially the foul air condition. The recycling of ELVs is one of the approaches to improve or save the devastated environment. A hybrid model based on DEMATEL (decision making trial and evaluation laboratory) and intuitionistic fuzzy sets is applied to analyze the influential relationships among the criteria/factors of this problem. The DEMATEL technique has the advantage of identifying the source factors that have influences on the addressed performance gap, which has been applied in many MCDM studies [30-32] that require a systematic analysis for guiding improvements. The findings of this study provide meaningful insights for the associated industries and policy makers to refer.

The fourteenth paper [33], invited by this journal, discusses the financial performance (FP) of the high-tech industry; one of the presumptions is that high-tech companies' FP has strong ties with their R\&D decisions. Furthermore, this study set the objectives of profitability as two distinct measures: the gross and the net profitability ratios. If the right $R \& D$ investment may increase the profitability of a high-tech company, the associated R\&D expenses cannot be overlooked on the net profitability measure. The management teams (or DMs) usually have to compromise between the R\&D expenses and the expected subsequent profits. This study paid attention to this underexplored issue and proposed a two-stage hybrid multiple rule decision making (MRDM) $[3,13,34]$ approach to analyze this problem. At first, a rough set-based machine learning mechanism unravels the complicated logic/rules between R\&D expenses and the subsequent two profitability measures by examining the financial statements of a group of public-listed high-tech companies in Taiwan. In the next, a hybrid MCDM model is proposed (based on the learned rules from the first stage) to form a decision support system. The obtained system may support high-tech companies in selecting/ranking new R\&D projects based on its emphases on the two distinct profitability measures.

The last paper [35] shifts its focus to the topic of green marketing. Its specific aim is to support the promotion of green products in retail stores by analyzing customers' purchasing behavior. To meet this end, it adopted radio frequency identification (RFID) to track the shopping path data from customers in a large shopping center in Seoul (South Korea). The obtained results may serve as a decision-making reference for retailers to increase the awareness of green marketing as well as their revenues. In this 
study, the modeling by the MCDM method is not emphasized. However, by adopting the RFID trackers, the obtained data may generate meaningful insights for retailers to adjust or improve their green marketing strategies; this experimental design is the primary contribution of this study.

\section{Conclusions}

Most of the collected papers in this Special Issue adopt more than one method or technique, which seem to be intricate at first glance. Nevertheless, the ultimate reason for this outcome is not the development of a complicated model but is the complexity caused by the practical sustainability problems. In this Special Issue, researchers identify the importance and the specific requirements of each addressed sustainability problem, which lead to the reasoning of their invented or proposed hybrid MCDM approach. The associated logic is essential to persuade reviewers, other researchers, and even practitioners to have faith in their findings.

Aside from the modeling, several articles suggest using their hybrid approaches to support systematic improvements. The idea of continuous improvement is essential for sustainability, also a rising trend in MCDM research [3]. Conventional MCDM studies are inclined to solve a well-defined problem for ranking or optimization decisions; however, it would be more constructive and proactive to guide a systematic improvement based on limited resources. Policy or decision makers should not be satisfied with a fixed solution. The world today is facing severe challenges on nearly all fronts of sustainability, and obtaining a fixed solution for a problem is of less value than providing insights for pursuing improvements. It is also the hope of this Special Issue to contribute to both academia and practice in this new direction.

Author Contributions: This Editorial is mainly organized and written by K.-Y.S., and G.-H.T. highlighted the central themes of this article. G.-H.T. also led the editorial procedures for this Special Issue.

Acknowledgments: Two grants, which both came from the Ministry of Science and Technology (MOST) of Taiwan, provided financial support for the editing of this article. The first one is under the grant number MOST-104-2410-H-305-052-MY3, and the second one is MOST-105-2410-H-034-019-MY2. The authors are grateful for those funding.

Conflicts of Interest: The authors declare no conflict of interest. The funding sponsors had no role in the analyses, interpretation, and conclusion of this Editorial.

\section{References}

1. Hopwood, B.; Mellor, M.; O’Brien, G. Sustainable development: Mapping different approaches. Sustain. Dev. 2005, 13, 38-52. [CrossRef]

2. Berk, R.A.; Freedman, D.A. Statistical assumptions as empirical commitments. In Law, Punishment, and Social Control: Essays in Honor of Sheldon Messinger; Aldine de Gruyter: Berlin, Germany, 2003; pp. 235-254. ISBN 9780202307015.

3. Tzeng, G.H.; Shen, K.Y. New Concepts and Trends of Hybrid Multiple Criteria Decision Making; CRC Press, Taylor \& Francis Group: Boca Raton, FL, USA, 2017; ISBN 9781498777087.

4. Zavadskas, E.K.; Govindan, K.; Antucheviciene, J.; Turskis, Z. Hybrid multiple criteria decision-making methods: A review of applications for sustainability issues. Econ. Res. 2016, 29, 857-887. [CrossRef]

5. Jordan, M.I.; Mitchell, T.M. Machine learning: Trends, perspectives, and prospects. Science 2015, 349, $255-260$. [CrossRef] [PubMed]

6. Simon, H.A. Bounded rationality in social science: Today and tomorrow. Mind Soc. 2000, 1, 25-39. [CrossRef]

7. Saaty, T.L. How to make a decision: The analytic hierarchy process. Interfaces 1994, 24, 19-43. [CrossRef]

8. Saaty, T.L. The analytic network process. In Decision Making with the Analytic Network Process; Springer: Boston, MA, USA, 2006; pp. 1-26.

9. Fontela, E.; Gabus, A. (Eds.) The DEMATEL Observe; Technical Report; Battelle Institute, Geneva Research Center: Geneva, Switzerland, 1976.

10. Shen, K.Y.; Yan, M.R.; Tzeng, G.H. Combining VIKOR-DANP model for glamor stock selection and stock performance improvement. Knowl.-Based Syst. 2014, 58, 86-97. [CrossRef] 
11. Zavadskas, E.K.; Turskis, Z.; Kildienè, S. State of art surveys of overviews on MCDM/MADM methods. Technol. Econ. Dev. Econ. 2014, 20, 165-179. [CrossRef]

12. Kahraman, C.; Onar, S.C.; Oztaysi, B. Fuzzy multicriteria decision-making: A literature review. Int. J. Comput. Intell. Syst. 2015, 8, 637-666. [CrossRef]

13. Shen, K.Y.; Zavadskas, E.K.; Tzeng, G.H. Updated discussions on "Hybrid multiple criteria decision-making methods: A review of applications for sustainability issues". Econ. Res.-Ekonomska Istraživanja 2018, in press.

14. Gong, Q.; Lei, J.; Qiao, H.; Qiu, J. Risk assessment for distribution systems using an improved PEM-based method considering wind and photovoltaic power distribution. Sustainability 2017, 9, 491. [CrossRef]

15. Lee, P.; Park, Y.J. Eco-efficiency evaluation considering environmental stringency. Sustainability 2017, 9, 661. [CrossRef]

16. Cook, W.D.; Seiford, L.M. Data envelopment analysis (DEA)-Thirty years on. Eur. J. Oper. Res. 2009, 192, 1-17. [CrossRef]

17. Tzeng, G.H.; Huang, J.J. Fuzzy Multiple Objective Decision Making; CRC Press, Taylor \& Francis Group: Boca Raton, FL, USA, 2013; ISBN 9781466554627.

18. Padmanathan, K.; Govindarajan, U.; Ramachandaramurthy, V.K.; Selvi, T.S.O. Multiple criteria decision making (MCDM) based economic analysis of solar PV system with respect to performance investigation for Indian market. Sustainability 2017, 9, 820. [CrossRef]

19. Battisti, F.; Guarini, M.R.; Chiovitti, A. The assessment of real estate initiatives to be included in the socially-responsible funds. Sustainability 2017, 9, 973. [CrossRef]

20. Jin, S.H.; Yun, H.Y.; Jeong, S.J.; Kim, K.S. Hybrid and cooperative strategies using harmony search and artificial immune systems for solving the nurse rostering problem. Sustainability 2017, 9, 1090. [CrossRef]

21. Debnath, A.; Roy, J.; Kar, S.; Zavadskas, E.K.; Antucheviciene, J. A hybrid MCDM approach for strategic project portfolio selection of agro by-products. Sustainability 2017, 9, 1302. [CrossRef]

22. Cheng, C.H.; Liou, J.J.; Chiu, C.Y. A consistent fuzzy preference relations based ANP model for R\&D project selection. Sustainability 2017, 9, 1352. [CrossRef]

23. Wang, G.; Tian, X.; Hu, Y.; Evans, R.D.; Tian, M.; Wang, R. Manufacturing process innovation-oriented knowledge evaluation using MCDM and fuzzy linguistic computing in an open innovation environment. Sustainability 2017, 9, 1630. [CrossRef]

24. Zhang, R. Sustainable scheduling of cloth production processes by multi-objective genetic algorithm with Tabu-enhanced local search. Sustainability 2017, 9, 1754. [CrossRef]

25. Liou, J.J.; Lu, M.T.; Hu, S.K.; Cheng, C.H.; Chuang, Y.C. A hybrid MCDM model for improving the electronic health record to better serve client needs. Sustainability 2017, 9, 1819. [CrossRef]

26. Baker, J. The technology-organization-environment framework. In Information Systems Theory; Springer: New York, NY, USA, 2012; pp. 231-245.

27. Chi, G.; Zhang, Z. Multi criteria credit rating model for small enterprise using a nonparametric method. Sustainability 2017, 9, 1834. [CrossRef]

28. Gan, L.; Wang, L.; Hu, L. Gathered village location optimization for Chinese sustainable urbanization using an integrated MODM approach under bi-uncertain environment. Sustainability 2017, 9, 1907. [CrossRef]

29. Gan, J.; Luo, L. Using DEMATEL and intuitionistic fuzzy sets to identify critical factors influencing the recycling rate of end-of-life vehicles in China. Sustainability 2017, 9, 1873. [CrossRef]

30. Keskin, G.A. Using integrated fuzzy DEMATEL and fuzzy C-means algorithm for supplier evaluation and selection. Int. J. Prod. Res. 2015, 53, 3586-3602. [CrossRef]

31. Wu, K.J.; Cui, L.; Tseng, M.L.; Hu, J.; Huy, P.M. Applying big data with fuzzy DEMATEL to discover the critical factors for employee engagement in developing sustainability for the hospitality industry under uncertainty. In Supply Chain Management in the Big Data Era; IGI Global: Hershey, PA, USA, 2017; pp. $218-253$.

32. Si, S.L.; You, X.Y.; Liu, H.C.; Zhang, P. DEMATEL technique: A systematic review of the state-of-the-art literature on methodologies and applications. Math. Probl. Eng. 2018, 3696457. [CrossRef]

33. Shen, K.Y.; Yan, M.R.; Tzeng, G.H. Exploring R\&D influences on financial performance for business sustainability considering dual profitability objectives. Sustainability 2017, 9, 1964. [CrossRef] 
34. Shen, K.Y.; Tzeng, G.H. Contextual improvement planning by fuzzy-rough machine learning: A novel bipolar approach for business analytics. Int. J. Fuzzy Syst. 2016, 18, 940-955. [CrossRef]

35. Syaekhoni, M.A.; Alfian, G.; Kwon, Y.S. Customer purchasing behavior analysis as alternatives for supporting in-store green marketing decision-making. Sustainability 2017, 9, 2008. [CrossRef]

(C) 2018 by the authors. Licensee MDPI, Basel, Switzerland. This article is an open access article distributed under the terms and conditions of the Creative Commons Attribution (CC BY) license (http:/ / creativecommons.org/licenses/by/4.0/). 